\title{
But, Do I Need a College Degree?: Understanding Perceptions of College and Career Readiness among Students Enrolled in a Career and Technical High School
}

\section{Genia M. Bettencourt ${ }^{1}$ (D) . Chrystal A. George Mwangi ${ }^{2}$ (D) Keisha L. Green ${ }^{3}$ (D) Daniel Morales Morales ${ }^{3}$ (D)}

Accepted: 14 October 2021 / Published online: 25 November 2021

(c) The Author(s), under exclusive licence to Springer Nature B.V. 2021

\begin{abstract}
Career and technical education (CTE) and college preparation curriculum in high school are often treated as mutually exclusive options rather than integrated, symbiotic tracks. However, increasingly career fields require some postsecondary education, and access to four-year college degrees are important for long-term earnings and mobility. In this two-year case study, we examined how 16 juniors enrolled in a CTE high school described and perceived their college and career aspirations. Our findings revealed that participants saw vocational and academic goals as mutually beneficial but experienced them through distinctive pathways, a disconnect amplified by a lack of resources in our sample site. While mechanisms to promote collegegoing existed, they were often only available to subsets of students and of limited utility. From this research, we suggest that the education system should expand dual enrollment opportunities, provide mentorship of diverse career possibilities, and begin integration between college and career planning earlier in students' schooling. Moreover, we examine the possibilities demonstrated by this case study for K-16 pathways and how postsecondary institutions can meaningfully engage with CTE schools to support this integration.
\end{abstract}

Keywords College access · College preparation · Career and technical education . Case study

Genia M. Bettencourt

Genia.m.bettencourt@memphis.edu

1 University of Memphis, Memphis, TN 38111, USA

2 George Mason University, Fairfax, VA 22030, USA

3 University of Massachusetts Amherst, Amherst, MA, USA 
For high school students in career and technical education (CTE) programs in secondary schools, there is increasingly an expectation that vocational elements include a strong academic focus to prepare students for successful educational and workforce endeavors. In 2006, the passage of the Carl D. Perkins Career and Technical Education Act sought to increase the quality of technical education and has been subsequently reauthorized, most recently in 2018 (Ujifusa, 2018). However, CTE programs may fall short of a true integration of academic and career preparation that supports equitable access to higher education as compared to traditional college preparatory academic tracks. The unequal access is particularly troubling as marginalized groups across race/ethnicity, gender, and socioeconomic backgrounds have historically been tracked into vocational programs in high school, resulting in lesser access to educational resources and reification of inequitable educational and workforce outcomes (Bozick \& Dalton, 2013; Giani, 2017).

College access and choice models often begin with the premise that a student wants to go to college, but simply needs the tools and readiness to be able to do so (Cabrera \& La Nasa, 2000; Perna, 2006). While prior studies examine programs designed to improve college readiness, such as dual enrollment or dual credit (An, 2013; Ozmun, 2013), these studies fail to comprehensive examine how these efforts influence of impact CTE students. Here, we argue for stronger secondary and postsecondary partnerships that integrate CTE with college preparation to provide students with greater opportunities beyond high-school. Our study shares the results of a two-year case study on the perceptions of and experiences with the collegegoing process for students enrolled at a CTE high school. Specifically, we ask the research question, how do CTE students describe and perceive their college and career aspirations?

\section{Literature Review}

The participants in this study were enrolled in a CTE high school and were exposed to numerous college-going initiatives throughout our research. To provide context, we discuss CTE and college preparation literature. We use the term non-CTE to refer to students who were enrolled in other secondary pathways including college preparatory and general education.

\section{Career and Technical Education (CTE)}

CTE utilizes both structural and instructional approaches to shape schools, programs, curriculum, and instruction (Brand et al., 2013). The National Association of State Directors of Career Technical Education Consortium outlined 16 clusters of CTE programs that included food service, computer technology, and finance. These programs receive federal support through the Carl D. Perkins Career and Technical Education Act (Perkins IV, 2006), which provided increased focus on the academic success of CTE students, replaced the word vocational with career and technical education, and maintained a funding split between secondary and postsecondary 
opportunities. The Perkins Act aimed to reform the stereotypes of low-level courses and job training traditionally associated with vocational training and instead promote comprehensive college and career readiness (Brand et al., 2013).

Conversations about CTE often center educational equity as CTE has both the potential to reinforce educational stratification and to promote economic opportunity through employment (Bozick \& Dalton, 2013). Historically, CTE was used to segregate students from college going pathways, so that "in large urban districts it has too often been a 'dumping ground' for low-income and minority youth" (Schwartz, 2014 , p. 25). Contemporary policymakers are hesitant to be seen as tracking students into CTE (Kelley et al., 2015), particularly as postsecondary pathways continue to be heavily shaped by race and class (e.g., Xing et al., 2019). However, CTE has also supported marginalized populations. For example, students with disabilities in CTE have had higher rates of employment during and after high school (Rabren et al., 2014; Wagner et al., 2015).

After high school graduation, CTE students are more likely to delay their educational goals or pursue shorter-term career interests (Laird et al., 2006). When they do enroll, CTE students are more likely to enroll in community colleges and earn a certificate or associate degree, but less likely to enroll in four-year institutions (Dietrich et al., 2016; Stevens et al., 2019). While little research has examined CTE high school students who enroll in a community college and transfer to a fouryear (Hioki et al., 2015), existing empirical data suggests that the transfer pathway is highly distinctive by CTE fields (Gottfried \& Plasman, 2018a).

\section{College Preparation}

High schools are a key hub of college information and college-going aspirations. However, college preparation efforts across high schools vary widely. In one foundational study, McDonough (1997) found that schools possess different cultures regarding college-going and postsecondary planning, a phenomenon described as organizational habitus. More recently, Jack's (2019) work demonstrated that poor and working-class students attending affluent high schools received crucial forms of college knowledge through their secondary environments. Indeed, attendance at a well-resourced high school transformed the experiences of the poor and working-class students studied (labeled as the privileged poor) and provided them with knowledge of college akin to their middle- and upper-class peers. Thus, the culture and resources within high schools, including CTE focused schools, can have a direct impact on how students are exposed to college as an option. Prior research has shown that while CTE courses have been found to lower the chances of dropout and increase the chances of on-time graduation, they have not been found to have an impact on college enrollment (Gottfried \& Plasman, 2018b).

Within high school environments, counselors are crucial figures in support pathways to college-going. Counselors can have positive and significant influence on students' postsecondary enrollment (Robinson \& Roska, 2013). However, many counselors contend with high student caseloads, increased responsibilities, and inconsistent training that create barriers in their work (Perna et al., 2008). 
Resultantly, school counselors often disproportionately spend most of their time on the students who need the most help (Perna et al., 2008). School support is supplemented by familial support, as parental encouragement that can impact institutional choice and enrollment (Engberg \& Allen, 2011). Specifically, for Latinx students such as those in this study, families have contributed emotional support around college preparation by offering dichos (motivational sayings) and consejos (wisdom or advice) (Kiyama \& Rios-Aguilar, 2018; Luedke, 2020). Yet, despite these mechanisms, the onus for college preparation largely falls on students to seek information (Perna et al., 2008).

In this study, we examine both CTE and college preparation efforts as they shape the college and career aspirations of students in this study. Such inquiry illuminates how students are exposed to different opportunities, which ultimately frames what choices are seen as viable for students as they form postsecondary plans (Iloh, 2019).

\section{Conceptual Framework}

The concept of capital helps to illustrate the skills, resources, and knowledge required to gain access to college (Cabrera \& La Nasa, 2000; Perna, 2000). Perna (2000) defines capital as "resources that may be invested to enhance profitability, productivity, and enhance upward mobility" (p. 73). The types of capital often used in this literature are those defined by Pierre Bourdieu (1986) as cultural capital (e.g., education, language), social capital (e.g., social networks, connections), and economic capital (e.g., money, material possessions). Two forms of capital inform this study.

Schulz and Bischoff (2009) define college capital as "the capital required to value, pursue, and complete a four-year degree, a credential institutionalized by society as capital with economic value" (p. 10). We apply this form of capital to consider how CTE high school students perceive the importance of a college degree (value a degree) and have the knowledge and resources necessary to successfully engage in the college-going process (pursue and complete a degree). Although college capital provides a direct lens for understanding access to college, we also recognize that language and processes often prioritize dominant cultural norms or engage a deficit perspective of minoritized students (Rhoades, 2014; Serna \& Woulfe, 2017).

To resist that approach, we integrate community cultural wealth (CCW) into our conceptual framework, which provides an applied approach to critical race theory (Yosso, 2005). CCW "is an array of knowledge, skills, abilities, and contacts possessed and utilized by socially marginalized groups to survive and resist macro- and micro-forms of oppression" (Yosso, 2005, p. 77). Cultural wealth identifies unacknowledged forms of capital and focuses on assets students bring to their school context (Villalpando \& Solorzano, 2005). Specifically, our study utilizes aspirational capital, which Yosso (2005) defines as, "the ability to maintain hopes and dreams for the future, even in the face of real and perceived barriers" (p. 77). This form of capital allows one to maintain aspirations for better circumstances even without the present means to achieve them (Yosso, 2005). This study examined the aspirational 
capital that students brought to and developed within their educational experiences. It also allowed us to consider students' post-high school career plans and aspirations beyond four-year college degree pathways.

\section{Methods}

This paper stems from a two-year case study of students enrolled in an English Language Arts (ELA) class during their junior year in high school, which met every other day for 90 minutes over one academic year with the authors of this article (i.e., the teaching and research team). We continued to meet with these students on a semi-regular basis during their senior year to check-in around their academic experiences, engage in career and college planning, and provide support and resources. Case study is an appropriate method when the researcher wants to explore contextual conditions critical to the phenomenon of study (Yin, 2017). In this study, the ELA class was defined as the case because we were seeking to explore and interpret the contextual conditions critical to how the course functioned and was implemented. Students taking the course were defined as embedded units within the case to recognize their unique lived experiences; this article stems from their narratives about post-high school/college preparation. We defined this case study as a unique case (Baxter \& Jack, 2008), which provides a context in which CTE students focused on college options and pathways as part of their curriculum. While this ELA class is not a typical case within CTE programs, given the need to integrate preparation for college pathways into CTE programs, our case may provide critical insights for CTE programs to consider if interested in pursuing that goal. Here, our analysis focuses on achieving an in-depth understanding of the context, concepts, and processes found in the case (Baxter \& Jack, 2008).

\section{Research Site and Sample}

Hillside Technical High School (HTHS; pseudonym) served as the location for this study. Located in Hillside, an urban community in the northeastern United States, HTHS is a career and technical high school that serves a predominantly Puerto Rican student population. At the time of this study, $80 \%$ of HTHS students identified as Hispanic/Latinx, 85\% came from low-income backgrounds, and nearly $50 \%$ reported that English was not their first language.

Participants for this study were selected due to their enrollment in an 11th-grade pre-Advanced Placement English Language Arts (ELA) class. The course was taught by the authors of this article, two faculty members (George Mwangi and Green), and two doctoral research assistants (Bettencourt and Morales). Fifteen students were nominated by HTHS administration to be enrolled in the course. Most students identified within the Latinx diaspora (13) - mainly Puerto Rican, with Mexican and Dominican Republican also represented - while two students were white or biracial. Nine identified as women and six as men. The content of the course included current events and contemporary issues, culturally relevant literature, and a youth 
participatory action research project on the school-to-prison pipeline. To learn more about the course, see Bettencourt et al. (2020), Green et al. (2020), and Morales Morales et al. (2017).

In addition to their academic coursework, students had the opportunity to choose different career fields to focus on during their time at HTHS as part of CTE. These programs, commonly referred to as shops, spanned such subject matter as culinary arts, cosmetology, health science, auto mechanics, and carpentry. Students spent approximately half of their time in shop, learning the technical skills and applications behind their selected trades. CTE options in the HTHS school district are focused on workforce development. While there are partnerships with the local community college to strengthen CTE programming at HTHS, the partnership is focused on career development, not college preparation.

\section{Data Collection}

Case studies often utilize multiple data points (Mertens, 2005). During the first year of the project, we spent approximately 2 to 2.5 hours at the research site every other day for an academic school year (a total of 114 contact hours). Approximately 90 minutes were spent on classroom instruction and 30 to 60 minutes engaging with ELA students informally, course planning, and debriefing. During the second year, we spent 1 to 1.5 hours every other week engaging in college and career planning with the students for a total of approximately 60 hours. Throughout our interactions, we collected data via participant observations, individual interviews, focus groups, and students' photographs, written narratives, and reflections.

This paper centers specifically on individual semi-structured interviews with students, field notes/reflexive memos written by the researchers, and internal correspondence within the research team such as email and shared documents. The interviews focused on the students' educational experiences and experiences with the ELA course and dual enrollment, concerns about college-going and plans after high school, and issues related to their critical awareness. Team members also wrote individual reflections during and after class sessions and regularly sent email messages to share classroom reflections and engage in course planning.

\section{Data Analysis}

While our larger study focused on the high school class, this article focuses on college and career aspirations and preparation, which emerged during our initial data analysis of the second year of the project (the participants' $12^{\text {th }}$ grade year). The prominence of the theme warranted a separate in-depth analysis.

Subsequently, we sought to further understand and analyze this theme by developing a research question centered on it and engaging in inductive analysis as a team to determine major patterns and themes across the participants' experiences. To begin this analysis, we read through all data collected through the project to identify the pieces most relevant to the research question. We then reviewed these selected data and wrote memos to record initial reflections and potential patterns (Merriam \& 
Tisdell, 2016; Simons, 2009). The team met to discuss memos and together identified inductive codes from the patterns we viewed in the data. These codes included evolving post-high school plans, tensions in college planning, and critical thinking. We next developed deductive codes, which are codes that are generated from one's framework or extant literature (Merriam \& Tisdell, 2016; Simons, 2009). In our case, we developed codes that reflected college capital and aspirational capital, which included college preparation skills, college knowledge, and future aspirations. After coding the data using inductive and deductive codes, we drew connections across the open coded data to develop broader categories that became the themes within our findings. For example, we saw how data coded under "future aspirations" and "tensions in college planning" also connected to participants' CTE schooling context and socialization, which became the first finding discussed within this article. As our team developed our findings, we used the data as evidence of our interpretations and analysis (Guest \& MacQueen, 2008). Finally, all team members reviewed the findings to promote consistency and foster a collaborative understanding of the data (Guest \& MacQueen, 2008).

\section{Trustworthiness}

Our research team enhanced the trustworthiness of our findings (Lincoln \& Guba, 1985) in multiple ways. We triangulated our data by using multiple data sources to support our emerging interpretations (Tracy, 2010). We also integrated analyst triangulation by having multiple our research team members implement data collection and analysis (Denzin, 1978). As researchers, we acknowledged that our identities intersected with the study and shaped our perceptions of students' narratives. Our research team included one white American woman who identified as a firstgeneration college student; two Black American women who were tenure track faculty; and one non-U.S.-born Latino man whose first language was Spanish. Thus, we shared some identities and experiences with the students in the ELA class who were predominantly racially minoritized, bilingual, and first-generation college students. However, our research team members were not local to the Hillside community prior to the study, nor worked formally for the Hillside school district. Thus, we worked to ensure the trustworthiness of our data by engaging in reflexivity about our interpretations of what we were experiencing throughout the study and during data analysis.

\section{Limitations}

Several limitations that frame this study. First, the students who participated in this study were nominated for the ELA course by HTHS administrators, who designated the course as pre-Advanced Placement without consultation of the teaching team. Our participants were largely considered to be some of the most academically accomplished and college-bound students at HTHS. Thus, it is important to note that our findings here are not necessarily reflective of all HTHS students, nor all CTE students. Second, it is important to note that HTHS is not reflective of all CTE high schools. Prior to our arrival at HTHS, the school was designated as failing by 
the state and had come under the oversight of a conservatorship. Secondary schools with more resources likely have more integration of college preparation and CTE coursework.

\section{Findings}

Four themes emerged in response to our research question. The first theme described how participants' college and career aspirations were integrated and linked to their CTE socialization. The second and third themes emphasized students' perceptions of their career readiness and college readiness, respectively. The final theme illuminated the primary opportunities for college preparation available. The individual student narratives presented within each section provide evidence to support the themes and reflect patterns found across our data.

\section{"You can go to college and have a job" - College and Career Aspirations}

While most participants in this study were not committed to immediately enrolling in college after high school, it was important to them to keep the option available. Connie shared that she was interested in going to college after graduation, but "if it is possible that my credits could be transferred to a technical school, I'll take advantage of that. I want to be first more certified in my trade before I go to [college]." Like Connie, many students wanted to utilize their technical training after high school but did not see this choice as separate from college attendance. Therefore, although HTHS focused on CTE, that did not prevent students from developing their college aspirations. As Mario explained, "I'm learning the trade so when I come out of high school, I can get a job...But I'm planning on going to college. [HTHS] helps you with both."

Many students saw college and career goals as intertwined, in which the academic knowledge provided by a college degree complemented the careers they were developing in vocational training. Teresa, Aileen, Stacey, and Connie all saw college degrees as important tools to one day run their own businesses in their trade. Teresa explained that to eventually run a successful hair salon, she needed the knowledge provided by business classes at the local community college: "I will have to go through two years of college to know how to handle my money smartly, keep customers, how to order things in an affordable way, and how to keep my business open." Thus, participants saw postsecondary education as a long-term goal to enhance the preparation they were receiving in high school and obtain additional certification.

While most students described some intrinsic desire to attend college, some were cautious about its feasibility. College aspirations were limited for many participants due to financial concerns. Not only would college attendance mean that the students would not be earning money in a career immediately, but higher education was seen as unaffordable. Jose expressed concerns about taking on debt for college, sharing, "I don't want to drop like $\$ 40,000$ a year on some college and not get to do what 
I'm majoring for." In this case, a lack of knowledge about different funding structures and resources for college had a direct impact on what students saw as possible. For some participants, going directly into the workforce was a clearer pathway to financial stability. Dan explained, "I just want to be somewhere doing electrical, something making money...that's the reason I chose my shop was for the money." Thus, students balanced an immediate need to earn money and the ability to do so with their CTE training, with their long-term goals to build careers that could be enhanced by a college degree.

\section{"I am only going to be out in the field knowing basic things" - Career Readiness}

The perceptions that students had regarding their career preparation varied widely. Yvette felt prepared in her Certified Nurse Assistant (CNA) field because of the mixture of academics and technical training available, noting "we do math in shop, we do anatomy in shop, we do sciences." Though in the same shop, Laura disagreed. She shared that her CNA teacher "is only involved with some of the kids," those most struggling, leaving Laura alone to master the curriculum.

Students enrolled at HTHS both to get a job after high school and because the CTE learning environment was appealing. Dan shared, "I came here because I was not interested in sitting in a classroom all day. I wanted to go to shop, get hands-on, and maybe get a job straight out of high school." However, the limited resources at HTHS made it difficult for all students to practice their skills. Dan commented that the electrical program at HTHS was strong in his first two years, when students were involved in different hands-on projects. He compared that experience to his junior year where "it's all repetitive." Juan visited HTHS when he was in middle school on a tour. Juan shared,

It was different when I came on the tour before freshman year. I was still in $8^{\text {th }}$ grade. They brought us around [HTHS], kids were working, kids were literally working, the shops were flooded...Now, there are more people dropping out than working.

Students perceived diminishing resources and shifts in the CTE curriculum as part of larger community disinvestment in the success of HTHS students. These concerns were amplified by a lack of partnerships between HTHS and local businesses, which if a key component of successful CTE programs (Schwartz, 2014; Shulock et al., 2011).

The dilution of CTE education left the students uncertain about their level of preparation for a career. Some students, such as Mario, felt empowered for success. However, participants such as Connie (welding), Dan (electrical training), and Juan (carpentry) had concerns about the lack of preparation and resources in their respective shops. Connie felt prepared for her career in welding but expressed concerns that the curriculum was not as rigorous as possible. She stated,

I just don't feel like I am being taught as intermediate as I should be, which is making me feel dumbed down in my shop and within the school. The school, in 
general, is just like "here let me give you simple math" and then give you something complicated right after it and expect you to just do it.

Connie went on to say that she felt unprepared because "I am only going to be out in the field knowing basic things about the shop." Jose feared that his credentials in electrical work were not as rigorous because of the limited opportunities provided at HTHS. He shared that his mathematics teacher told his class that their technical certification was "not as good as a license from another school because what you learn in HTHS [is] lowered down and basic." For participants that expected they would graduate from HTHS and be career-ready, the realization that they were less prepared than they anticipated became a major concern.

\section{"I'm not as prepared for college... for a job, I feel prepared"- College Readiness}

Despite concerns that some students shared about their career readiness, they explained HTHS provided a more robust CTE foundation than college preparation. Mario stated,

Right now, academic wise, I'm not as prepared for college due to the lack of teachers. Every semester we're always having a different teacher for every class. I don't feel as prepared, academic wise. For a job, I feel prepared because I'm learning new things every single day, every day in shop. Shop is spot on. Academic wise, it's like 50-50.

Similarly, Yvette expressed, "the classes weren't challenging enough...I like the shop, they educate us, but academics, not challenging, not enough work." Therefore, while an earlier section highlighted students having both college-going and CTE career aspirations, they did not always feel a strong sense of college readiness.

Students saw the lack of focus on academics at HTHS as a disadvantage in being able to craft competitive college applications. Relatedly, some students described a lack of high school support for the college-going process. Connie explained,

They haven't taken me aside and told me how to do this, this, this, and this to get better and go to college. I don't think this school actually cares if you go to college or not. They just want you to get out.

One example that illustrated the tension between CTE and college preparation was the perceived differences between HTHS and the other local high school, Hillside High. Students described Hillside High as better resourced with a higher caliber of academic education. Students often compared both schools and critiqued the perception that they were less intelligent because they selected to participate in CTE.

Within a 30-mile radius of HTHS, postsecondary options spanned multiple community colleges, public state institutions, elite liberal arts colleges, and small private universities. However, our participants had little exposure to most of these universities. Lily explained to a member of our ELA class teaching team that "the only college [HTHS students] have ever been to is [a local community college] and that they have never heard of any opportunities at any other colleges, neither of scholarships or any kind of financial help." College preparation at HTHS was sparse, with the limited opportunities available occurring primarily during the students' senior year. 


\section{"Give Me More of a Head Start to College" - Opportunities for College Preparation}

While resources for college planning were limited, there were some available at HTHS. In particular, participants frequently noted the HTHS guidance counselor, the ELA teaching team and course, and dual enrollment at the local community college, Hillside Community College (HCC), as key supports in their postsecondary planning.

Guidance Counselor Participants primarily discussed their guidance counselor as the main source of college information and support available. For example, Laura learned about the dual enrollment program from her guidance counselor. She explained that her guidance counselor "wanted us to do a test, the placement test, because that's how we applied. They do a placement test and whatever score we get, we choose our classes." Indeed, the HTHS counselor possessed a wealth of college-related information about college fairs, pre-college programs, and scholarship applications. However, she was also the only guidance counselor for the entire 12th-grade class and often struggled to support students' college-going needs. The limited resources echoed participants' view of a lack of support for college-going across HTHS.

ELA Teaching Team Due to the unique context of our study, the four members of our teaching team were available and accessible to students to discuss college plans. In some cases, we were able to directly provide opportunities such as helping students to register for dual enrollment, organizing college visits, and coaching students through the Free Application for Federal Student Aid (FAFSA). In other cases, we collected information from students and shared resources provided by the guidance counselor. Thus, the team served as a conduit for information, as well as a tangible resource for participants. One example was students asking the two college professors on our team for letters of recommendation because "getting a college professor's recommendation would be a great help." Being taught by college professors also provided students with confidence that they could handle college-level work. Connie noted that although students did not receive college credit for the course, "it still gives you, like, the college experience." In many ways, the curriculum, critical thinking, and behavioral expectations of the course were aligned with an undergraduate class.

However, it is important to note the limited sphere within which the class and teaching team operated. Students were selected for our course by their high school administrators. The course was not integrated into the school's formal curriculum (it was not a secondary-postsecondary learning options (SPLOs) or dual credit course) and our teaching team did not have access to funds or staff support. Although we provided students with information about pre-college programs, college classes, and visits, we could not ensure students would attend. Many opportunities for college exposure were held on the weekends, during the summer, or outside of our class time, which made them inaccessible to students without transportation or with competing priorities (e.g., athletics, jobs, family responsibilities). 
Dual Enrollment In addition to the guidance counselor and ELA class, students described the dual enrollment program with HCC as important to their college aspirations. Dual enrollment students had to complete the community college application and the FAFSA, and were able to receive college credit for their dual enrollment courses. As Connie explained, "You're just taking college classes while you are in high school. It gives you college credit and high school credit. It helps you to use the credits for college after you graduate." Jose, despite his reluctance to attend college after high school, enrolled in dual enrollment "because I thought overall it was a good idea financially. And that if I do end up going to college, I have a couple of extra credits just to help me get started."

Attending a dual enrollment class provided insight into college and had a clear connection to students' educational goals. Laura chose to participate because "I thought I would get more experience of being in college and I also thought that the credits would give me more of a head start to college too." Similar to the ELA class, participating in dual enrollment also helped students feel more confident in doing college-level work. Jose noted that "if I wanted to go to college, I feel more like I know what I'm doing." One of the main critiques of the program was that participants had very little time on the HCC campus and had to leave immediately after class due to the transportation system.

Like the ELA course, it is important to note that not all students participated in dual enrollment. Some students were unable to enroll because they did not pass the placement test or missed the application deadline. Moreover, opportunities to learn about dual enrollment seemed only available to some students. Several participants, like Frank, discussed hearing about dual enrollment for the first time in our class.

I heard about [dual enrollment] when [ELA instructors] introduced it to us. I really didn't know that...You guys are pretty much the reason why I'm in dual enrollment. If I didn't have you guys for teachers, I would have never been in dual enrollment.

To streamline the process, we invited a staff member from the community college to our class help our students start the application process. Although any student at the high school could try to participate in dual enrollment, many may not have been aware of the program or provided with the resources needed to apply. Thus, while dual enrollment provided important resources and an important entry point to college, it was not easily accessible to all students. Even for students in the ELA class, only a subgroup was both eligible and chose to participate in dual enrollment.

\section{Discussion}

Findings from this study demonstrate that CTE participants in this study often saw value in pursuing a college degree and sought to integrate career aspirations with higher education, thus rejecting what Bailey and Belfield (2019) described as the false dichotomy between CTE and college preparation. Participants' perspectives were reflective of Yosso's (2005) definition of aspirational capital, which suggests the ability to maintain a positive outlook on future goals even 
as challenges and barriers (real or perceived) are present. Participants routinely encountered messages that HTHS students were not smart enough for college, beginning in middle school when students had to choose between the HTHS, the CTE option, and HHS, the traditional college preparatory high school. Though many of our participants chose HTHS due to the desire for applied education and career opportunities, the educational system literally marked this choice as separate by creating a binary discourse around the two options in Hillside. This perception was reinforced by the limited information and preparation for college provided by HTHS when students arrived, reflecting an organizational habitus that was primarily career-focused (McDonough, 1997). While our participants were able to imagine alternative possibilities and hope for themselves, the lack of intentional nurturing and opportunities to reinforce aspirational capital may limit its utility or prevent it from being converted to college capital.

Additionally, the value of a college degree is only one component of how Schulz and Bischoff (2009) define college capital (other components include capital necessary to pursue and complete a degree). Yet, the literature demonstrates that while aspirations for college among students of Color are often higher than that of their white counterparts, far fewer students of Color end up enrolling in college (Bergerson, 2009). Known as the aspiration-attainment gap, researchers find that while most minoritized students and their families place a high value on education, these expectations are discouraged over time by limited resources, lack of support, inadequate access to information, financial issues, perceptions of low returns on education investments, and tracking into nonacademic high school courses (Flennaugh \& Howard, 2016). Furthermore, many students who think they are college-bound are often prepared by their high schools to be work-bound (Rosenbaum, 2001), which may be even more likely within the CTE context. In this study, whether students were interested in going to college or not, institutional constraints at multiple levels did not always develop or reinforce students' aspirational capital.

HTHS did have some mechanisms (e.g., dual enrollment) that provided opportunities to build additional knowledge, skills, and resources to pursue and eventually attain a college degree. Sadly, these opportunities were not equitable across all HTHS students and were often reserved for students believed to be "college-worthy" (Convertino \& Graboski-Bauer, 2018). The college-going opportunities provided to students were also not fully integrated into the curriculum or practices of the high school, which left it up to students to draw connections between their CTE training and college. As HTHS was largely under resourced, the guidance counselor often did not have the ability to help facilitate these connections (Perna et al., 2008). As training on CTE is uneven, even absent, across teacher preparation programs, disconnect is amplified by the fact that many educators may be new to building these connections (O'Connor, 2012). Our project was unique in that our teaching team provided a vital form of support around college knowledge, from concrete opportunities (e.g., field trips to local universities, workshops on dual enrollment and FAFSA) to the opportunity to engage directly with higher education faculty. Such an example shows how K-16 pathways can provide additional resources and support within the local community (see Bettencourt et al., 2020) and partner with uniquely 
with CTE high schools to help facilitate possible integration across college and career pathways.

The value students placed on going to college was heavily integrated into their perceptions of how a college degree could further reinforce their vocational/technical training and career plans. CTE schools like HTHS are in a unique position to engage in job counseling as well as draw connections between career and college readiness. Unfortunately, as an under-resourced high school, HTHS lacked structures to support students in either college or career readiness. Although the high school offered programs to support students' college capital and reinforce their aspirational capital, they were not operationalized in a holistic way that made students collegeready. This aligns with literature demonstrating that students in secondary-postsecondary learning options (e.g., programs that link high school and college) report being academically motivated, but do not perceive high levels of college and academic self-efficacy (Ozmun, 2013). Providing students with opportunities external to the functions of the curriculum and daily practices of the school may suggest a college-for-all perspective, but this cannot be enacted without explicit connections to a high school's efforts and resources (Barnes \& Slate, 2013; Rosenbaum, 2001).

\section{Implications}

While CTE in high school can provide a valuable foundation for career success, to access stable jobs students increasingly need some form of postsecondary education. The National Skills Coalition (2017) reported that middle-skills jobs, which require some types of postsecondary education and training comprised 53\% of all jobs. High-skill jobs (aligned with four-year and graduate degrees) comprised $31 \%$; low-skills jobs represented just $16 \%$ of positions. In the financial recession tied to COVID-19, job losses have been worst amongst individuals with high school degrees or less, and higher for individuals with an associate's degree or some college than those with a bachelor's degrees (Fowers, 2021). Strengthening the pathways between secondary and postsecondary education is crucial to support individuals in pursuing economic stability.

Findings from our study provide several implications to support CTE students' post-high school planning. One implication for education practitioners is to more intentionally conceptualize and develop connections between CTE and college readiness to foster students' post-high school opportunities. SPLOs like dual enrollment and dual credit can be used to build coalitions between high schools, colleges, and local communities. Given our participants' positive experiences taking dual enrollment courses, we suggest that community colleges are well-positioned to partner even further with CTE high schools to provide programming and resources. However, our involvement shows that all colleges and universities can play a role in this integration by engaging with students and exposing them to available pathways.

For higher education institutions, there is a need to collect more data about CTE students to inform practice (Gottfried \& Plasman, 2018a; Shulock et al., 2011). Our study is an example; we did not longitudinally follow our participants, and thus do not have comprehensive information about how their perceptions in high school 
ultimately shaped their postsecondary attainment. Previous research on college student success often assumes a normative population (e.g., between ages 18-22, attending school full time), neglecting CTE students who may be career-focused, older, and in pursuit of different degree pathways (Hirschy et al., 2011).

Additionally, existing CTE and college going partnerships largely exist at the community college level, where students can take courses towards professional certification, associate's degrees, or transfer requirements. However, bachelor's degrees continue to be associated with significant gains over the course of an individual's lifetime (Mayhew et al., 2016). Rather than supporting students who wish to pursue CTE and a bachelor's degree, transfer pathways are often heavily bifurcated. Technical certificates only somewhat serve as a step to associate's degrees, while associate degrees in CTE subjects are generally not steps to bachelor's degrees (Shulock et al., 2011). Aligning expectations and coursework is one valuable approach. Another is to integrate more opportunities in college to pursue academic degrees with career experience. For example, Kelley and colleagues (2015) shared the example of a cooperative education program at the University of Cincinnati where students blend coursework with work experience, alternating terms between office and classroom. This partnership facilitated engagement with various industries, offered students a salary while working, and guided students to a bachelor's degree.

Acknowledgements This research aided by funding support from the Massachusetts Society of Professors and the College of Education at the University of Massachusetts Amherst. We thank the students and community of Hillside Technical High School for their collaboration in this research and the reviewers and editorial board of Innovative Higher Education for their valuable feedback on this manuscript.

Available of Data and Material Not publicly available.

Funding A small grant in support of this research was awarded by the Massachusetts Society of Professors.

\section{Declarations}

Conflict of Interest Not applicable.

Code Availability Not publicly available.

\section{References}

An, B. P. (2013). The influence of dual enrollment on academic performance and college readiness: Differences by socioeconomic status. Research in Higher Education, 54(4), 407-432.

Bailey, T. R., \& Belfield, C. R. (2019). The false dichotomy between academic learning \& occupational skills. Daedalus, 148(4), 164-178. https://doi.org/10.1162/DAED_a_01765.

Barnes, W., \& Slate, J. R. (2013). College-readiness is not one-size-fits-all. Current Issues in Education, 16(1), 1-13.

Baxter, P., \& Jack, S. (2008). Qualitative case study methodology: Study design and implementation for novice researchers. The Qualitative Report, 13(4), 544-559.

Bergerson, A. A. (2009). College choice and access to college: Moving policies, research, and practice to the 21st century. ASHE Higher Education Report, 35(4). Jossey-Bass. 
Bettencourt, G. M., George Mwangi, C. A., Green, K. L., \& Morales Morales, D. (2020). High school -university collaborations for Latinx student success: Navigating the political reality. Journal of Higher Education Outreach and Engagement, 24(1), 17-41.

Bourdieu, P. (1986). Forms of capital. In J. G. Richardson (Ed). Handbook of theory and research for sociology of education (pp. 241-258). Greenwood.

Bozick, R., \& Dalton, B. (2013). Balancing career and technical education with academic coursework: The consequences for mathematics achievement in high school. Educational Evaluation and Policy Analysis, 35(2), 123-183.

Brand, B., Valent, A., \& Browning, A. (2013). How career and technical education can help students be college and career ready: A primer. American Institutes for Research. Retrieved from http://www. ccrscenter.org/sites/default/files/CCRS\%20Primer\%20Brief.pdf.

Cabrera, A. F. \& La Nasa, S. M. (2000). Overcoming the tasks on the path to college for America's disadvantaged. In A. F. Cabrera \& S. M. La Nasa (Eds.), Understanding the college choice of disadvantaged students. New Directions for Institutional Research, 107, 31-43. Jossey-Bass.

Carl D. Perkins Career and Technical Act U.S.C. 109 Source $\$ 250$ (2006).

Convertino, C., \& Graboski-Bauer, A. (2018). College readiness versus college worthiness: Examining the role of principal beliefs on college readiness initiatives in an urban U.S. high school. The Urban Review, 50(1), 45-68.

Denzin, N. K. (1978). The research act: A theoretical introduction to sociological methods (2nd ed.). McGraw-Hill.

Dietrich, C., Lichtenberger, E., \& Kamalludeen, R. (2016). Predicting community college outcomes: Does high school CTE participation have a significant effect? Journal of Career and Technical Education, 31(1), 9-32.

Engberg, M. E., \& Allen, D. J. (2011). Uncontrolled destinies: Improving opportunity for low-income students in American higher education. Research in Higher Education, 52, 786-807.

Flennaugh, T. K. \& Howard, T. C. (2016). Creating postsecondary access and opportunity for urban youth. In T. Howard, J. D. Tunstall, \& T. K. Flennaugh (Eds.) Expanding college access for urban youth: What schools and colleges can do (pp. 1-19). Teachers College Press.

Fowers, A. (2021). The economy is getting even worse for Americans with a high school diploma or less. The Washington Post. https:/www.washingtonpost.com/business/2021/01/27/economy-is-gettingeven-worse-americans-with-high-school-degrees-or-less-education/?arc404=true

Giani, M. S. (2019). Does vocational still imply tracking? Examining the evolution of career and technical education curricular policy in Texas. Educational Policy, 33(7), 1002-1046. https://doi.org/10. $1177 / 0895904817745375$.

Giani, M., Alexander, C., \& Reyes, P. (2014). Exploring variation in the impact of dual-credit coursework on postsecondary outcomes: A quasi-experimental analysis of Texas students. The High School Journal, 97(4), 200-218.

Gottfried, M. A., \& Plasman, J. S. (2018a). From secondary to postsecondary: Charting an engineering career and technical education pathway. Journal of Engineering Education, 107(4), 531-555. https://doi.org/10.1002/jee.20236.

Gottfried, M. A., \& Plasman, J. S. (2018b). Linking the timing of career and technical education coursetaking with high school dropout and college-going behavior. American Educational Research Journal, 55(2), 325-361. https://doi.org/10.3102/0002831217734805.

Green, K. L., Morales Morales, D., Bettencourt, G. M., \& George Mwangi, C. A. (2020). (Responding to) youth epistemologies to create a third space: A reclamation of learning in an English language arts classroom. English Teaching: Practice and Critique, 19(3), 303-316. https://doi.org/10.1108/ ETPC-08-2019-0108

Guest, G., \& MacQueen, K. M. (Eds.). (2008). In Handbook for team-based qualitative research. Altamira Press.

Hioki, W., Lester, D., \& Martinez, M. (2015). Predisposition factors of career and technical education transfer students: A hermeneutic phenomenology study. Community College Enterprise, 21(2), 9-28.

Hirschy, A. S., Bremer, C. D., \& Castellano, M. (2011). Career and technical education (CTE) student success in community colleges: A conceptual model. Community College Review, 39(3), 296-318. https://doi.org/10.1177/0091552111416349.

Iloh, C. (2019). An alternative to college "choice" models and frameworks: The Iloh model of collegegoing decisions and trajectories. College and University, 94(4), 2-9. 
Hoffman, N., Vargas, J., \& Santos, J. (2009). New directions for dual enrollment: Creating stronger pathways from high school through college. New Directions for Community Colleges, 145, 43-58.

Jack, A. A. (2019). The privileged poor: How elite colleges are failing disadvantaged students. Harvard University Press.

Kelly, A. P., James, K. J., Lautzenheiser, D. K., Deane, K.C., \& Columbus, R. (2015). Building paths to the middle class: Innovations in career and technical education. American Enterprise Institute. https://www.aei.org/research-products/report/building-paths-to-the-middle-class-innovations-incareer-and-technical-education/

Kiyama, J. M., \& Rios-Aguilar, C. (2018). Funds of knowledge in higher education: Honoring students' cultural experiences and resources as strengths. Routledge.

Laird, J., Chen, Z., Levesque, K, \& Owings, J. (2006). The postsecondary educational experiences of high school career and technical education concentrators. National Center for Educational Statistics.

Lincoln, Y. S., \& Guba, E. G. (1985). Naturalistic inquiry. Sage.

Luedke, C. L. (2020). Developing a college-going habitus: How first-generation Latina/o/x students bidirectionally exchange familial funds of knowledge and capital within their familias. The Journal of Higher Education, 91(7), 1028-1052. https://doi.org/10.1080/00221546.2020.1726702.

Mayhew, M. J., Rockenbach, A. N., Bowman, N. A., Seifert, T. A. D., \& Wolniak, G. C., with Pascarella, E. T., \& Terenzini, P. T. (2016). How college affects students: $21^{\text {st }}$ century evidence that higher education works (volume 3). Jossey-Bass.

McDonough, P. M. (1997). Choosing colleges: How social class and schools structure opportunity. SUNY Press.

Merriam, S. B., \& Tisdell, E. J. (2016). Qualitative research: A guide to design and implementation ( $^{\text {th }}$ ed.). Jossey-Bass.

Mertens, D. M. (2005). Research and evaluation in education and psychology: Integrating diversity with quantitative, qualitative, and mixed methods ( $2^{\text {nd }}$ ed.). SAGE Publications.

Morales Morales, D., Bettencourt, G. M., Green, K., \& George Mwangi, C. A. (2017). "I want to know about everything that's happening in the world": Enhancing critical awareness through youth participatory action research with Latinx youths. The Educational Forum, 81(4), 401-417. https://doi. org/10.1080/00131725.2017.1350236

O'Connor, P. J. (2012). The professional development needs of academic teachers adding career-technical education licenses. Journal of Career and Technical Education, 27(1), 34-47.

Ozmun, C. D. (2013). College and academic self-efficacy as antecedents for high school dual-credit enrollment. The community college Enterprise, 19(1), 61-72.

Perna, L. W. (2000). Racial and ethnic group differences in college enrollment decisions. In a. Cabrera \& S. La Nasa (Eds.) understanding the college choice of disadvantaged students. New Directions for Institutional Research, 107, 65-83.

Perna, L. W. (2006). Study college access and choice: A proposed conceptual model. In J. C. Smart (Ed.), Higher education: Handbook of theory and research (Vol. 21, pp. 99-157). Springer.

Perna, L. W., Rowan-Kenyon, H. T., Thomas, S. L., Bell, A., Anderson, A., \& R., \& Li, C. (2008). The role of college counseling in shaping college opportunity: Variations across high schools. The Review of Higher Education, 31(2), 131-159. https://doi.org/10.1353/rhe.2007.0073.

Rabren, K., Carpenter, J., Dunn, C., \& Carney, J. S. (2014). Actions against poverty: The impact of career technical education. Career development and transition for exceptional individuals, 37(1), 29-39. https://doi.org/10.1177/2165143414522091.

Rhoades, G. (2014). The higher education we choose, collectively: Reembodying and repoliticizing choice. The Journal of Higher Education, 85(6), 917-930.

Robinson, K. J., \& Roska, J. (2016). Counselors, information, and high school college-going culture: Inequalities in the college application process. Research in Higher Education, 57, 845-868. https:// doi.org/10.1007/s11162-016-9406-2.

Rosenbaum, J. E. (2001). Beyond college for all. Russell Sage.

Schulz, S. A. \& Bischoff, R. (2009). Measuring college capital [PowerPoint slides]. The College Board Western Regional Forum. Retrieved from https://cerpp.usc.edu/files/2013/11/MeasuringColleg eCapitalFINAL.pdf

Schwartz, R. B. (2014). The pursuit of pathways: Combining rigorous academics with career training. American Education, 25-41. https://www.aft.org/ae/fall2014/schwartz

Serna, G. R., \& Woulfe, R. (2017). Social reproduction and college access: Current evidence, context, and potential alternatives. Critical Questions in Education, 8(1), 1-16. 
Shulock, N., C. Moore, \& Offenstein, J., (2011). The road less traveled: Realizing the potential of career technical education in the California community colleges. Institute for Higher Education Leadership and Policy. https://www.mtsac.edu/president/cabinet-notes/Road\%20Less\%20Traveled.pdf

Simons, H. (2009). Case study research in practice. SAGE Publications.

Stevens, A. H., Kurlaender, M., \& Grosz, M. (2019). Career technical education and labor market outcomes: Evidence from California community colleges. Journal of Human Resources, 54(4), 986-1036.

Tracy, S. J. (2010). Qualitative quality: Eight "big-tent" criteria for excellent qualitative research. Qualitative Inquiry, 16(10), 837-851. https://doi.org/10.1177/10778004103812.

Ujifusa, A. (2018). Donald Trump signs first major education policy bill of his presidency. Education Week. https://www.edweek.org/teaching-learning/ donald-trump-signs-first-major-education-policy-bill-of-his-presidency/2018/07

Wagner, M. M., Newman, L. A., \& Javitz, H. S. (2015). The benefits of high school career and technical education (CTE) for youth with learning disabilities. Journal of Learning Disabilities, 49(6), 658-670. https://doi.org/10.1177/0022219415574774.

Villalpando, O., \& Solorzano, D. G. (2005). The role of culture in college preparation programs: A review of the research literature. In W. G. Tierney, Z. B. Corwin, \& J. E. Colyar (Eds.), Preparing for college: Nine elements of effective outreach (pp. 13-28). SUNY Press.

Xing, X., Huerta, M., \& Garza, T. (2019). College and career preparation activities and their influence on post-high school education and work attainment. Journal of Career and Technical Education, 34(1), $8-28$.

Yin, R. K. (2017). Case study research: Design and methods (6 $6^{\text {th }}$ ed.). Sage.

Yosso, T. J. (2005). Whose culture has capital? A critical race theory discussion of community cultural wealth. Race, Ethnicity, and Education, 8(1), 69-91.

Publisher's Note Springer Nature remains neutral with regard to jurisdictional claims in published maps and institutional affiliations.

Genia M. Bettencourt is an Assistant Professor of Higher and Adult Education at the University of Memphis.

Chrystal A. George Mwangi is an Associate Professor in the Higher Education Program at George Mason University.

Keisha L. Green is an Associate Professor of Teacher Education and School Improvement at the University of Massachusetts Amherst.

Daniel Morales Morales is a Doctoral Candidate in Language, Literacy, and Culture at the University of Massachusetts Amherst. 